VOX PATRUM 24 (2004) t. $46-47$

Jacek SIERADZAN

(Białystok, Uniwersytet $w$ Białymstoku)

\title{
JEZUS CHRYSTUS JAKO MODEL DLA POSTACI APOLLONIUSZA Z TIANY
}

\begin{abstract}
Apolloniusza z Tiany uważa się za neopitagorejskiego filozofa ${ }^{1}$ i mędrca ${ }^{2}$, maga $^{3}$, taumaturga ${ }^{4}$, czarownika ${ }^{5}$, szamana ${ }^{6}$, egzorcystę, interpretatora snów
\end{abstract}

${ }^{1}$ Za pitagorejczyka uznawali Apolloniusza: Flawiusz Filostratos (Vita Apollonii I 7-8, 14, 32), XII-wieczny kronikarz Zonaras (Epitome Historiarum XI 19), por. M. Dzielska, Apolloniusz z Tiany: Legenda i rzeczywistość, Kraków 1983, 22. Wspólcześnie w ten sposób pisali o nim m.in. M. Dzielska (tamże, s. 140) i G. Luck (Witches and Sorcerers in Classical Literature, w: B. Ankarloo - S. Clark (red.), The Athlone History of Witchcraft and Magic in Europe, vol. 2, London 1999, 130). Z kolei dla M. Szarmacha Apolloniusz to „kaznodzieja” (Wstęp do: Flawiusz Filostratos, Żywot Apolloniosa z Tiany, tłum. M. Szarmach, Toruń 2000, 13).

${ }^{2}$ Wg B.F. Harrisa Apolloniusz był wędrownym pitagorejskim mędrcem, por. Apollonius of Tyana: Fact and Fiction, „Journal of Religious History” 5 (1969) 198.

${ }^{3}$ Magiem (mägos) byl wg Kasjusza Diona (Historia Romana LXXVIII 18, 4, ed. E. Cary, Dio's Roman History with an English Translation, vol. 9, Cambridge 1929, 326). Ammianus Marcellinus porównał Apolloniusza do Hermesa Trismegistosa i Plotyna (Res gestae XXI 14, 5 , thum. pol. J. Lewandowski: Dzieje rzymskie, I, Warszawa 2001, 367). Zarówno Hermesa jak i Plotyna zaś wiązano z magią. O Plotynie jako magu por. np. P. Merlan, Plotinus and Magic, "Isis" 44 (1953) 341-348. Apolloniusz byl magiem także wg Zonarasa (zob. przypis 1), G. Lucka (Witches and Sorcerers in Classical Literature, s. 133) i M. Szarmacha (Wstęp, s. 13).

${ }^{4}$ Za cudotwórcę uważał Apolloniusza jego biograf i główny twórca jego legendy Flawiusz Filostratos (por. punkt $26 \mathrm{w}$ tekście poniżej). Taumaturgicznych umiejętności Apolloniusza nie odrzucał nawet pisarz chrześcijański Euzebiusz z Cezarei, wedle którego cudów dokonywał on przy pomocy demonów (Contra Hieroclem 31, w: F.C. Conybeare, Philostratus: The Life of Apolloniuus of Tyana, The Epistles of Apollonius and the Treatise of Eusebilus with an English Translation, vol. 2, Cambridge 1948, 565).

${ }^{5}$ Flawiusz Filostratos w wielu miejscach Żywota Apoloniusza (IV 18; VII 17, 33-34; VIII 30) wspomina, że Apolloniusza uznawano za czarownika czyli goetę ( $g$ öes). Za czarownika uważali go też Kasjusz Dion (Historia Romana LXXVIII 18, 4, Cary, vol. 9, s. 326), Orygenes (Contra Celsum VI 41), a w IV wieku Synezjusz z Cyreny (Calvitii laudes 6), Izydor z Pelazjum (Epistolae I 398, w: Dzielska, Apolloniusz z Tiany, s. 121), oraz Euzebiusz z Nikomedii (gōetos, w: Eusebius, Contra Hieroclem 31, Conybeare s. 552). Współcześnie za czarownika uważa Apolloniusza G. Luck (Witches and Sorcerers in Classical Literature, s. 130).

"Por. B.L. Blackburn, "Miracle working theioi andres" in Hellenism (and Hellenistic Judaism), w: D. Wenham - C. Blomberg (red.), Gospel Perspectives: The Miracles of Jesus, vol. 6, Sheffield 1986, 191. 
i doradcę medycznego ${ }^{7}$. Dla jego zwolennika Flawiusza Filostratosa był „podobnym bogu daimonionem", a dla jego przeciwnika Lukiana - szalbierzem $^{9}$. Mimo iż źródła historyczne z I i II wieku nie wspominają o Apolloniu$\mathrm{szu}^{10}$, jego historyczność nie jest obecnie podawana w wątpliwość. ${ }^{11}$ Pierwszym historykiem, który pisał o nim, był Kasjusz Dion (ok. 155-235), autor Historii Rzymskiej powstałej ok. 200-222 roku ${ }^{12}$. Głównym źródłem dia poznania życia Apolloniusza jest powstały około 220 roku Żywot Apolloniusza $z$ Tiany pióra Flawiusza Filostratosa (178-248). Według niego i kilku badaczy współczesnych żył on od ok. 4/3 p.n.e. do ok. $96 / 97$ n.e. ${ }^{13}$, a zdaniem M. Dzielskiej od ok. 40 n.e. do ok. 120 n.e. ${ }^{14}$. Z powodu niepewnych przekazów nie wiadomo, co w Żywocie Apolloniusza jest prawdą, a co legendą. Wiadomo na pewno, że Apolloniusz byl autorem filozoficznego dzieła $O$ ofiarach (którego fragmenty zachowały się u Porfiriusza i Euzebiusza z Cezarei) ${ }^{15}$, oraz kilku listów ${ }^{16}$.

Zarówno w ewangelicznych przekazach o Jezusie, jak i w biografii Apolloniusza można znaleźć wiele wspólnych cech. Zdaniem J.Z. Smitha, aretalogie ${ }^{17}$ greckie (jak $O \dot{z} y c i u$ pitagorejskim Jamblicha czy Żywot Apolloniusza) oraz teksty ewangeliczne łączy wspólny motyw syna bożego, który zstępuje na ziemię, aby poprzez swoje działania ukazać ludziom ich niewiedzę; jego działania są tajemnicze i przekraczają ludzkie rozumienie ${ }^{18}$. Według M. Smitha,

7 Trzy ostatnie cechy dojrzał w Apolloniuszu B.F. Harris (Apollonius of Tyana, s. 198).

${ }^{8}$ Gr. daimōniōs te kai theíos (Vita Apollonii I 2, Conybeare, Philostratus, vol. 1, s. 8), a na pewno nie magiem czy goeta (Vita Apollonii V 12), bo wobec goecji Filostratos mial negatywne stanowisko (tamże VII 39). Tekst grecki Zywotu Apolloniusza Flawiusza Filostratosa podaję za: Conybeare, Philostratus, natomiast polski przekład podaję za tłumaczeniem I. Kani: Żywot Apolloniusza z Tiany, Kraków 1997.

${ }^{9}$ Por. Alexander 5, tlum. W. Madyda: Lukian, Dialogi, t. 2, Wrocław 1962, 160.

${ }^{10}$ Por. Dzielska, Apolloniusz z Tiany, s. 7.

11 Wiadomo np., że żyjący w połowie II w. Mojragenes napisał o nim wspomnienia, które jednak nie zachowały się; por. Orygenes, Contra Celsum VI 41; Vita Apollonii I 3.

${ }^{12} \mathrm{Wg}$ niego Apolloniusz, będąc w 96 roku w Efezie, widział zabójstwo cesarza Domicjana w Rzymie (Historia Romana LXVII 18, Cary, vol. 8, s. 357-359; por. Vita Apollonii VIII 25-26).

${ }_{13}$ Por. Dzielska, Apolloniusz z Tiany, s. 23 i 33, przypis 30; zob. Vita Apollonii VIII 29.

14 Por. Dzielska, Apolloniusz z Tiany, s. 23 i 139. W kwestii datacji Apolloniusza zob. jej rozważania na s. 23-26.

15 Por. tamże, s. 140.

${ }^{16}$ Autorstwo niektórych listów zachowanych pod imieniem Apolloniusza podaje się w wątpliwość (Dzielska, Apolloniusz z Tiany, s. 26; Szarmach, Wstęp, s. 13). Jednak wg M. Dzielskiej, List 58 na pewno wyszedł spod pióra Apolloniusza (Apolloniusz z Tiany, s. 23-24 i 105).

17 Greckie słowo „aretalogia” (äretalōgia) pochodzi od äreta-lōgos, „interpretator cudów”. Jej łaciński odpowiednik aretalogus oznacza ,mówienie o cudach boga”. Jest to pojedyncza opowieś́ o cudach lub zbiór takich opowieści, majạcych na celu propagowanie bohatera i/lub bóstwa, któremu owe cuda przypisano, por. M. Snilh, Prolegomena to a Discussion of Aretalogies, Divine Men, The Gospel and Jesus, „Journal of IBiblical Literature” 90 (1971) 176.

${ }^{18}$ Por. J.Z. Smith, Good New' is No News: Aretalogy and Gospel, w: J. Neusner (red.), 
literatura tego typu odzwierciedlała i zaspokajała potrzeby ludzi końca anty$\mathrm{ku}^{19}$. Ponieważ biografia Apolloniusza jest o ponad wiek młodsza od Ewangelii, narzucającym się wnioskiem jest to, że jego curriculum vitae oparto właśnie na nich, tym bardziej, że między nimi można znaleźć wiele analogii ${ }^{20}$. Co do tego nie ma jednak zgodności między uczonymi ${ }^{21}$. Wydaje się jednak całkiem prawdopodobne, że Żywot Apolloniusza Flawiusza Filostratosa, który powstał na zamówienie cesarzowej Julii Domny, nie był tylko zwykłą „romansową biografią" ${ }^{22}$, ale raczej konterfektem „boskiego męża” (theios änēr), prezentującym wzorcowy żywot hellenistycznego bohatera i filozofa, mogący stanowić hellenistyczny odpowiednik ewangelicznego portretu Jezusa i powstały w obliczu rosnących wpływów chrześcijaństwa jako odpowiedź na nie ${ }^{23}$.

1) Obu przypisano boskie pochodzenie: Jezus był Synem Ducha Świętego (Mt 1, 18) i Synem Bożym (Mk 14, 61); Apolloniusz emanacją Proteusza ${ }^{24}$ i synem Zeusa ${ }^{25}$.

2) Obu uważano za bogów: Jezus był postacią Bożą (Flp 2, 6), Panem (Dz 2, 36) i „mądrością Bożą" (1 Kor 1, 24). Apolloniusza już za życia traktowano jak

Christianity, Judaism and Other Greco-Roman Cults: Studies for Morton Smith at Sixty, vol. 1, Leiden 1975, 36.

19 Por. Smith, Prolegomena to a Discussion of Aretalogies, Divine Men, The Gospel and Jesus, s. 180 .

${ }^{20}$ M. Józefowicz-Dzielska podkreśliła „uderzające podobieństwo" nauk Jezusa i Apolloniusza (,Vita Apolonii" Filostrata i jej związki z literaturq wczesnochrześcijańskq - stan badañ, SACh 2:1980, 129). Z kolei G. Luck zwrócil uwagę na "uderzające paralele" między Vita Apollonii a "kanonicznymi ewangeliami, Dziejami Apostolskimi i niektórymi apokryfami” (Witches and Sorcerers in Classical Literature, s. 136). Najczęściej przywoluje się podobieństwo opisów wskrzeszenia. W przypadku Jezusa chodzilo o córkę Jaira (Mk 5, 39-42), a w przypadku Apolloniusza o bezimienną dziewczynę (Vita Apollonii IV 45). M. Dzielska uznala to ostatnie za ryt nekromacji (Apolloniusz z Tiany, s. 69), a G. Petzke (Die Traditionen über Apollonius von Tyana, Leiden 1970, s. 129-130) i M. Szarmach ( $O$ cudzie Apolloniosa z Tyany u Filostrata (VA IV 45), w: I. Lewandowski - K. Liman [red.], Litteris vivere. Ksiega pamiatkowa ofiarowana Profesorowi Andrzejowi Wójcikowi, Poznań 1996, 68-70) za analogon wskrzeszenia córki Jaira.

${ }^{21} \mathrm{Wg}$ A. Fleury'ego i J.A. Froude Żywot Apolloniusza to kompilacja wątków z żywotów Szymona Maga, Jezusa i apostoła Pawła. F. Baur (w 1832 r.) oraz jego kontynuatorzy: L. Noack, J. Réville, R. Reitzenstein, J.S. Philimore, E. Norden, G. Herzog-Hauser, M.J. Schutz, B.F. Harris, G. Petzke i M. Szarmach podkreślali ich zależność od pism Nowego Testamentu i literatury apokryficznej. Z kolei C. Nielsen (w 1879 r.), J. Miller, E. Rohde, I. Levy, F. Grosso, T. Mantero byli przekonani, że legendy o Apolloniuszu powstały niezależnie od tradycji ewangelicznych, a ich bezpośrednim źródłem był neopitagoreizm. Tytuły prac wzmiankowanych tu autorów podają M. Józefowicz-Dzielska („Vita Apolonii” Filostrata $i$ jej związki z literaturą wczesnochrześcijań$s k q$, s. 129-135), oraz M. Szarmach (Wstęp, s. 22).

22 Tak uważa za włoskimi badaczami życia Apolloniusza (F. Lo Cascio i D. Del Corno) M. Szarmach, (Wstẹp, s. 15).

${ }^{23}$ Może o tym świadczyć np. uwaga G. Lucka, który doszukał się w Vita Apollonii ukrytej polemiki z chrześcijaństwem (Witches and Sorcerers in Classical Literature, s. 136).

24 Por. Vita Apollonii I 4.

${ }^{25}$ Por. tamże I 6. 
boga $^{26}$, nazywano godnym „miana boga”27. Według przypisywanych mu listów część ludzi uważała go za „równego bogom, a niektórzy nawet za boga”28. Co więcej: „nawet bogowie mówią o nim jako o «boskim mężu»"29.

3) Narodzinom obu towarzyszyły niezwykłe okoliczności. Narodziny Jezusa zostały zapowiedziane w wizji przez anioła: jego matce ( $\ k$ 1, 30-31) i Józefowi (Mt 1, 20-21). Miejsce jego urodzenia wskazała trzem magom ${ }^{30}$ gwiazda betlejemska. Matka Apolloniusza miała przed jego urodzeniem wizję Proteusza, który zapowiedział, że urodzi się jako jej syn ${ }^{31}$; jego narodzinom towarzyszyło uderzenie pioruna ${ }^{32}$.

4) Obaj prowadzili ascetyczny tryb życia: Jezus przebywał na pustyni (Mt 4, 2-11; Mk 1, 35); Apolloniusz od 16 roku życia był pitagorejczykiem ${ }^{33}$.

5) Zarówno Jezus (Mk 1,13), jak i Apolloniusz ${ }^{34}$ na początku swojej kariery mieli demoniczne wizje.

6) Obaj modlili się: Jezus do niebiańskiego Ojca ( $Ł k$ 11, 2); A polloniusz do bogów $^{35}$ i Heraklesa ${ }^{36}$.

7) Obaj mieli poważanie u bóstw. Bóg nazwał Jezusa swoim umiłowanym synem $(\mathrm{Mk} 1,11)$. Bóg Asklepios mówił w wizjach o uzdrowicielskich właściwościach Apolloniusza ${ }^{37}$ dlatego "sami bogowie mieli go w poważaniu"38.

8) Zarówno Jezus (Mk 1, 36; 3, 7), jak i Apolloniusz ${ }^{39}$ posiadali licznych uczniów, w towarzystwie których podróżowali i którzy opuścili ich w godzinie próby: uczniowie Jezusa uciekli po jego aresztowaniu (Mk 14, 50), a spośród 34 uczniów Apolloniusza aż 26 opuścilo go przed wizytą u Nerona, ${ }^{40}$ a tylko 10 udało się wraz z nim w niebezpieczną podróż do Egiptu ${ }^{41}$.

${ }^{26}$ Por. tamże I 19; VII 21.

${ }^{27}$ Por. tamże VIII 5.

${ }^{28}$ Epistula 44, Conybeare, vol. 2, s. 437.

29 Epistula 48, tamże, s. 445.

30 Tekst grecki Mt 2,1. 7 nazywa ich magami (mägoi). Owych „magów” Biblia protestancka określa mianem „mędrców”, w tradycji katolickiej funkcjonują jako królowie, a Ewangelia Hebrajczyków nazywa ich „wróźami”, por. M. Starowieyski (red.), Apokryfy Nowego Testamentu, I, Lublin 1986, 76.

31 Por. Vita Apollonii I 5.

32 Por. tamże I 4.

${ }^{33}$ Apolloniusz żył w celibacie, nie pił alkoholu, był wegetarianinem, chodził boso, nosil dhugie włosy (Vita Apollonii I 7-8), przez pięć lat zachowywał milczenie ( $\$ 14$ ), nie bral kąpieli w gorącej wodzie (\$16), nie bral udziału w składaniu krwawych ofiar (\$32), mówiąc, trzymał wzrok wbity w ziemię ( $\$ 10)$; dzięki temu, że nie ulegał namiętnościom, panowal nad bólem (VII 36).

34 Vita Apollonii II 4.

35 Por. tamże I 35; IV 40.

36 Por. tamże VIII 7.

${ }^{37}$ Por. tamze I 8-9.

38 Tamże I 9.

39 Por. tamże IV 37; VI 3.

40 Por. tamże IV 37.

${ }^{41}$ Por. tamże V 17-36. 
9) Obaj nauczali w świątyniach ${ }^{42}$. Jezus nauczal w głównych ośrodkach palestyńskich $^{43}$, Apolloniusz przekazywał nauki w głównych ośrodkach greckich $^{44}$ i śródziemnomorskich ${ }^{45}$.

10) Wypowiadali się w sposób enigmatyczny, używali stylu epigramatycznego: Jezus za pomocą logiów ${ }^{46}$; Apolloniusz stylem wyroczni ${ }^{47}$.

11) Zarówno Jezus ${ }^{48}$, jak i Apolloniusz ${ }^{49}$ dokonali reformy życia religijnego, m.in. wprowadzając nowe ceremonie: Jezus Eucharystię (Mk 14, 22-24), a Apolloniusz napitek Tantala o właściwościach nektaru ${ }^{50}$.

12) Obaj posiadali tajemną mądrość, którą przekazywali niewielu wtajemniczonym ${ }^{51}$.

13) Zarówno Jezus ${ }^{52}$, jak i Apolloniusz ${ }^{53}$ mieli charyzmatyczną osobowość, dzięki której wywierali wpływ na swoich współczesnych.

14) Obaj podkreślali znaczenie szacunku dla drugiego człowieka: Jezus przestrzegał, aby nikogo nie nazywać głupcem (Mt 5, 22); Apolloniusz przestrzegał, aby nie wyśmiewać się z nikogo ${ }^{54}$.

15) Obaj przedstawiali się jako pasterze: swoich zwolenników nazywali owcami, a przeciwników wilkami ${ }^{55}$.

16) Obaj weszli w konflikt $z$ autorytetami religijnymi swoich czasów. Jezus oskarżał faryzeuszy o hipokryzję (Mt 23) i przywiązywanie znaczenia do, w znacznej mierze martwych, pewnych aspektów tradycji (Mt 15, 1-20). Apolloniusz oskarżał kapłanów ateńskich o bluźnierstwo i arogancję ${ }^{56}$.

17) Zarówno Jezus ${ }^{57}$, jak i Apolloniusz ${ }^{58}$ protestowali przeciw tyrańskim rządom cesarza i ich popleczników.

\footnotetext{
${ }^{42}$ Por. Mk 6, 2; Vita Apollonii IV 2-3.

43 Por. Mk 3, 7-8. Nauczał m.in. w Jerychu (Mk 10, 46) i Jerozolimie (Mk 11-12).

44 Por. Vita Apollonii IV 1-34.

45 Por. tamże V 17-26.

${ }^{46}$ Por. Mt 5-6. Zbiór logiów przypisywanych Jezusowi zawiera Ewangelia Tomasza.

47 Por. Vita Apollonii I 17.

48 Jezus oczyścił świątynię z handlarzy (Mk 11, 15-17).

49 Ulepszal kult (Vita Apollonii I 16), przywracal dane obrzędy (IV 24), doradzal jak wzniesć ołtarz lub posąg (IV 1), jak i o jakiej porze czcić bóstwa (§ 19).

so Por. Vita Apollonii III 15, 32, 51.

51 Jezus przekazywal sekrety Królestwa Bożego (Mk 4, 10-12), Apolloniusz wraz z innymi pitagorejczykami wykonywał sekretne ceremonie (Vita Apollonii I 16).

${ }_{52}$ Pierwsi uczniowie poszli za Jezusem w chwili, gdy tego zażądał (Mk 1, 16-20).

53 Por. Vita Apollonii IV 2-3. W okresie pięcioletniego milczenia samą gestykulacją powstrzymał wybuch społecznego niezadowolenia (I 15). Sama jego obecność miała uspokajać siły natury

${ }^{54}$ Por. tamże IV 43.

55 Por. J 10, 11-12; Vita Apollonii VIII 22.

56 Por. Vita Apollonii IV 19.

57 Zapowiadal nadejście końca świata (Mk 13, 24-27).
} (IV 13). 
18) Obu więziono pod zarzutem prowadzenia tajnej działalności politycznej: Jezusa nazywano „złoczyńcą" (J 18, 30); Apolloniusza oskarżono o przygotowywanie spisku na życie Domicjana".

19) Obu sądzono jako buntowników ${ }^{60}$.

20) Jezusa stracono za uzurpację władzy królewskiej (Mt 27, 37); Apolloniusza cesarz uwolnił od zarzutów ${ }^{61}$.

21) Zarówno Jezusa (Mk 3, 22), jak i Apolloniusza ${ }^{62}$ oskarżano o praktykowanie magii przy pomocy demonów.

22) Mimo iż Jezus ${ }^{63}$ i Apolloniusz ${ }^{64}$ zapewniali, że nie praktykują magii, uważano ich za magów.

23) Co więcej, zarówno Jezusa ${ }^{65}$, jak i Apolloniusza ${ }^{66}$ oskarżano o praktykę „czarnej” magii.

24) Ich zwolennicy bronili ich przed oskarżeniami o praktykowanie magii, głosząc, że cudów dokonują dzięki tkwiącej w nich nadnaturalnej sile. Jezus czyni cuda dzięki mocy Bożej (Theou... dūnāmesi) ${ }^{67}$; Apolloniusz czynił je za sprawą nadnaturalnej mocy (daimonía kínēsei), objawionej mu przez bogów (theoi), a nie będącej wynikiem geocji68.

25) Umiejętności egzorcyzmowania obu przedstawiano jako dowód na to, że nie są magami ${ }^{69}$.

26) Obaj posiadali niezwykłe umiejętności, które czyniły z nich taumaturgów:

a) zdolności jasnowidzące ${ }^{70}$;

b) czytanie w umysłach innych ${ }^{71}$;

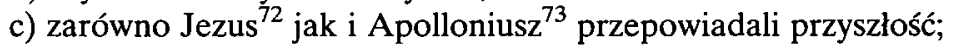

${ }^{58}$ Krytykowal rządy Nerona (Vita Apollonii IV 36, 42), Domicjana (VI 42) i innych tyranów (VII 4).

${ }^{59}$ Por. Vita Apollonii VII 20.

${ }^{60}$ Por. Mk 14, 53 - 15, 20; Vita Apollonii VIII 1-9.

61 Por. Vita Apollonii VIII 5.

62 Por. tamże IV 44.

63 Por. Origenes, Contra Celsum I 30; Tertullianus, Apologeticus 21, 17; 23, 12.

64 Por. Vita Apollonii IV 18; VII 17, 33-34; VIII 30; Origenes, Contra Celsum VI 41.

${ }^{65}$ Przypisywanie mu związków z z Belzebubem (Mt 9, 34; 12, 24), było równoznaczne z uznaniem go za czarnoksiężnika.

${ }^{66}$ Oskarżono go o złożenie ofiary z chłopca (Vita Apollonii VII 20). Kapłan ateński nie dopuścil go do wtajemniczeń podając jako powód to, że praktykuje goecję i zadaje się z demonami (IV 18). $\mathrm{Z}$ analogicznych przyczyn kapłani nie wpuścili go do wyroczni Trofoniosa w Lebadei (VIII 19).

67 Por. Dz 2, 22.

68 Por. Vita Apollonii V 12, Conybeare, vol. 1, s. 488.

${ }^{69}$ Por. Mk 3, 22-27; Vita Apollonii IV 19.

70 Jezus: Mk 5, 39; 14, 13; Apolloniusz: Vita Apollonii V 24.

71 Jezus: Mk 2, 8; 12, 15; Apolloniusz: Vita Apollonii V 24; VI 3.

72 Jezus przepowiadal przyszłość swoją (Mk 8, 1), innych ludzi $(9,1)$, klęski żywiołowe $(13$, 24-25), katastrofy, jakie spadną na miasta ( k 10, 13-16; 13, 34-35; 23, 28-30), oraz ogólne nieszczęścia (Mk 5, 39). 
d) zarówno Jezus ${ }^{74}$, jak i Apolloniusz ${ }^{75}$ posiadali zdolności uzdrawiające;

e) tak Jezus ${ }^{76}$, jak Apolloniusz ${ }^{77}$ niechętnie leczyli wszystkich;

f) obaj uzdrawiali też na odległość $\mathbf{c}^{78}$;

g) zarówno Jezus ${ }^{79}$, jak i Apolloniusz ${ }^{80}$ egzorcyzmowali demony;

h) obaj wskrzeszali zmarłych ${ }^{81}$;

i) obaj uciszali burzę na morzu ${ }^{82}$;

j) obaj uspokajali swoich uczniów, aby nie lękali się wodnego żywiołu ${ }^{83}$;

k) obu nie można było schwytać, kiedy tego nie chcieli ${ }^{84}$;

l) obaj stawali się niewidzialni ${ }^{85}$.

27) Zarówno Jezus ${ }^{86}$, jak i Apolloniusz ${ }^{87}$ zakończyli życie w sposób niezwykły. 28) Groby obu są nieznane ${ }^{88}$.

29) Po śmierci otaczano ich kultem: na bazie kultu Jezusa powstało chrześcijaństwo. Apolloniusza już za życia czczono jak boga ${ }^{89}$. Po jego śmierci cesarz Al ksander Sewer (222-235) oddawał mu cześć na równi z Abrahamem, Orfeuszem i Chrystusem ${ }^{90}$, a cesarz Aurelian (270-275) na życzenie Apolloniusza, który pojawił mu się $\mathbf{w}$ wizji na jawie i odwodził go od rzezi niewinnych, „obiecal mu poświęcić obraz, posągi i świątynię""91.

${ }^{73}$ Apolloniusz przepowiadal przyszłość swoją (Vita Apollonii VII 38), innych ludzi (I 12, 22; IV 18, 24; V 13, 24; VI 32), klęski żywiołowe (VII 41; Epistula 68), katastrofy, jakie spadną na miasta (Vita Apollonii IV 4), oraz ogólne nieszczęścia (VII 20).

74 Jezus leczył z ośmiu wymienionych z nazw chorób: gorączki (Mk 1, 30-31), trądu (1, 40-45), paraliżu (2, 3-12), krwotoku (5, 25-29), gluchoty (7, 31-35), slepoty $(8,22-25 ; 10,46-52)$, kalectwa (Łk 13, 10-17) i puchliny (14, 2-4). Mial też przywrócić do dawnego stanu uschłą rękę (Mk 3, 1-5); ponadto leczył z niewymienionych $z$ nazw chorób $(1,32-34 ; 3,10 ; 6,56)$.

75 Apolloniusz leczyl z trzech wymienionych z nazwy rodzajów chorób: puchliny wodnej (Vita Apollonii I 9), okulawień (III 39), wścieklizny (VI 43), oraz bliżej nieokreślonych chorób (IV 11); powstrzymywał też epidemie (§10).

${ }^{76}$ Nie chcial uzdrowić dziewczynki kananejskiej (Mk 7, 26-27).

$77 \mathrm{Za}$ namową Asklepiosa odmówił pośredniczenia w wyleczeniu człowieka bogatego, lecz nikczemnego (Vita Apollonii I 10).

78 Jezus: Mk 7, 25-30; Apolloniusz: Vita Apollonii 11138.

${ }^{79}$ Mk 1, 25-26; 3, 11. 22; demony wprowadził w stado świń $(5,13)$.

80 Vita Apollonii IV 20, 25; demona wprowadził w posąg (\$ 20).

81 Jezus: Mk 5, 39-42; Apolloniusz: Vita Apollonii IV 45.

82 Jezus: Mk 4, 37-39; Apolloniusz: Vita Apollonii IV 13.

83 Jezus: Mk 6, 50; Apolloniusz: Vita Apollonii IV 34.

84 Jezus: Łk 4, 29-30; Apolloniusz: Vita Apollonii VIII 30.

85 Jezus: Łk 24, 31; Apolloniusz: Vita Apollonii VIII 30.

86 Jezus wstąpił do nieba (Mk 15, 19; Łk 24, 51).

87 Zniknął w świątyni Ateny w Lindos lub w świątyni Artemidy Diktynna na Krecie (Vita Apollonii VIII 30).

88 Por. Vita Apollonii VIII 30.

89 Por. tamże VII 21; VIII 5.

90 Por. Aelius Lampridius, Alexander Severus 29, thum. H. Szelest: Historycy Cesarstwa Rzymskiego: Zywoty cesarzy od Hadriana do Numeriana, Warszawa 1966, 234.

91 Flavius Vopiscus, Divus Aurelianus 24, tamże, s. 383. 
$\mathrm{Na}$ podstawie powyższych uwag można powiedzieć, że Apolloniusz pod żadnym względem nie byl gorszy od Jezusa (poza tym, że Jezus leczył z ośmiu różnych rodzajów chorób, a Apolloniusz tylko z trzech), co więcej posiadı 10 innych umiejętności, których nie opanował Jezus.

\section{JESUS CHRIST AS THE MODEL FOR APOLLONIOS OF TYANA'S BIOGRAPHY}

(Summary)

In this short article the author present Jesus Christ of the Gospel as the model for the life of Apollonios of Tyana's biography of Flavius Filostratos. Author found out 28 analogies in hagiographies of both, and in addition 12 analogies in miracles activity. 